\title{
The challenge of restoring mesio-distal dimension: the rational use of the development of dental materials in Pediatric Dentistry
}

\author{
Sandra Meyfarth, ${ }^{1}$ Roberta Barcelos, ${ }^{2}$ Flavio Warol, ${ }^{2}$ Angela Scarparo ${ }^{2}$ \\ ${ }^{1}$ Posgraduate Program in Dentistry, School of Dentistry, Fluminense Federal University (UFF), Nova Friburgo, RJ, Brazil \\ ${ }^{2}$ Department of Specific Formation, School of Dentistry, Fluminense Federal University (UFF), Nova Friburgo, RJ, Brazil \\ - Conflicts of interest: none declared.
}

\section{Abstract}

Objective: the aim of this study was to present the versatility of bulk fill flow resin composite and regular resin composite used to restore mesio-distal space loss of a pediatric patient presenting caries lesions in the dental elements 74 and 75. Case Report: after treatment planning, restorative procedures with Bulk-fill composite and universal adhesive were performed in two visits, preceded by the use of orthodontic elastic rings to open interdental space between teeth to regain the needed space. Conclusion: the recovery of the space affected by caries is difficult to perform and it requires multiple dental office visits. However, when treatment is correctly conducted in association with new performed and allied to new technologies, it ensures the re-establishment of the arch length minimizing the sequels of caries disease. Keywords: Arch length; Dental caries; Mesio-distal space loss; Resin composite.

\section{Introduction}

$\mathrm{D}$ ental caries is the one of the most prevalent chronic diseases, and it is an important cause of oral pain and dental loss still today. ${ }^{1}$ The partial or total loss of dental structure can cause a reduction of the dental arch space provoking a structural and functional disequilibrium. ${ }^{2}$ Thus, to maintain arch length is very important for good masticatory function and the establishment of permanent dentition considering the optimal occlusion development. $^{3}$

The 2006-07 American Academy of Pediatric Dentistry guidelines state that the maintenance of space is essential to prevent the loss of arch length, diminishing arch width, and/or arch perimeter by guarantee the relative position of the existing dentition. ${ }^{4}$

Resin-based composites are the dental material most used on contemporary pediatric restorative dentistry. ${ }^{5}$ Primary teeth properly restored do not capable to spread of infection besides maintain space for the permanent dentition. Thus, the space maintenance should be taken into consideration when treatment planning and restoring primary molars. ${ }^{6}$ With the evolution of the aesthetic dentistry new adhesive systems and resin composite have been launched on the market. A new material class, the bulk-fill, has been introduced in the past few years. They are an attempt to minimizing the polymerization stress, besides speed up the restoration process by enabling up to 4 - or 5 - $\mathrm{mm}$ thick increments to be photoactived in one step, thus skipping the time-consuming layering process ${ }^{7}$, that is a prime factor when treating pediatric and non-collaborative patients. In the same way, the so-called "universal adhesives" have the potential to significantly simplify and expedite adhesive protocols. ${ }^{8}$

Based on that, the aim of this article is to report a case of a pediatric patient presenting caries lesions in the dental elements 74 and 75 with mesio-distal space loss. Restorative procedures were performed in two visits, preceded by teeth spacing and use of a Bulk-fill composite and universal adhesive.

\section{Case Report}

Patient M.M., female gender, 7 years old, presented in the clinical and radiographic exams, caries lesions in the dental elements 74 (occlusal-distal) and 75 (occlusal-mesial) and mesio-distal space loss as seen in Figure 1.

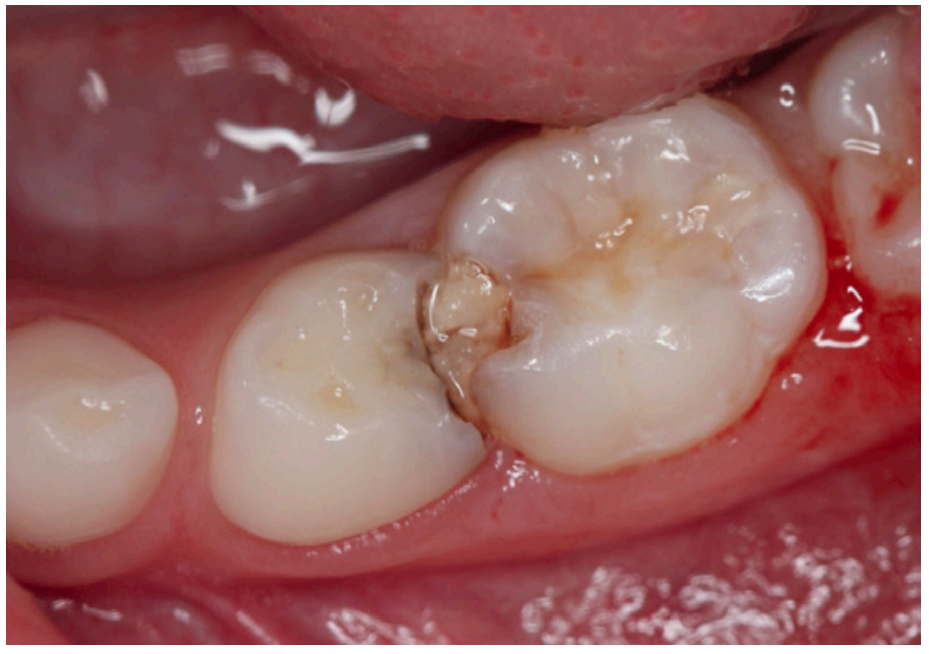

Figure 1. Initial aspect caries lesions in dental elements 74 (occlusal-distal) and 75 (occlusal-mesial) 
After treatment planning, it was decided to start treating the tooth 75 . The patient was anesthetized with $2 \%$ lidocaine. Then a rubber dam (Madeitex, São José dos Campos, SP) and clamp number 114-M (SS White Duflex, Rio de Janeiro, RJ) were used. Afterwards, the caries lesion was removed with high speed bur which gave a better observation made possible a better observation of the mesio-distal space loss, as shown in figure $2 \mathrm{~A}$. Then, a steel matrix was placed (figure 2B; note the enamel cervical wall) and considering the biological cycle of the tooth 74 , it was performed a restauration with resin composite.

Acid-etching: it was performed a selective enamel conditioning. The application was made with $37 \%$ phosphoric acid (Dentsply, Brazil) through the syringe (Figure 2C). After 15 seconds water was rinsed for 60 seconds and then dried until total evaporation from the cavity surface (Figure 2D).

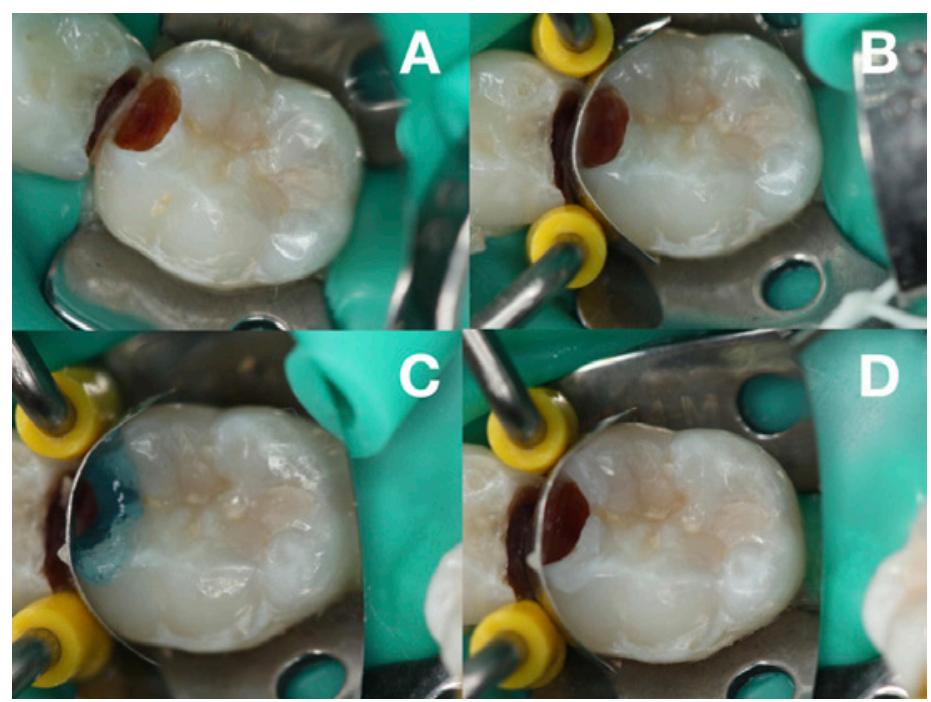

Figure 2. A) Caries lesion removed with high speed bur; B) Steel matrix placed (note the enamel cervical wall); C) Selective enamel acid etching with $37 \%$ phosphoric acid; D) Final aspect of enamel after elective enamel acid etching

Adhesive system: the adhesive system Ambar Universal (FGM, Joinville - SC, Brazil) was actively applied over the cavity surface for 20 seconds, according to the manufacturer's instructions (Figure 3A). The disposable brush was agitated on the cavity surface under manual pressure. Then, for complete evaporation of the solvent, a moderate jet of clean, dry air was applied close and sufficiently strong to keep the adhesive layer in slight motion. This evaporation of the solvent continued with more forced air until there were no movements on the adhesive for at least 5 seconds. Finally, the adhesive system was photo activated for 10 seconds.

Restorative procedure: after the adhesive system application, the cavity of tooth 74 was restored with resin composite bulk fill flow Opus (FGM, Joinville - SC, Brazil). It was applied in one increment of $4 \mathrm{~mm}$ (Figure 3B) and the final cover with resin composite Llis (FGM, Joinville - SC, Brazil) (Figure 3C). The final restoration is shown in figure 3D.

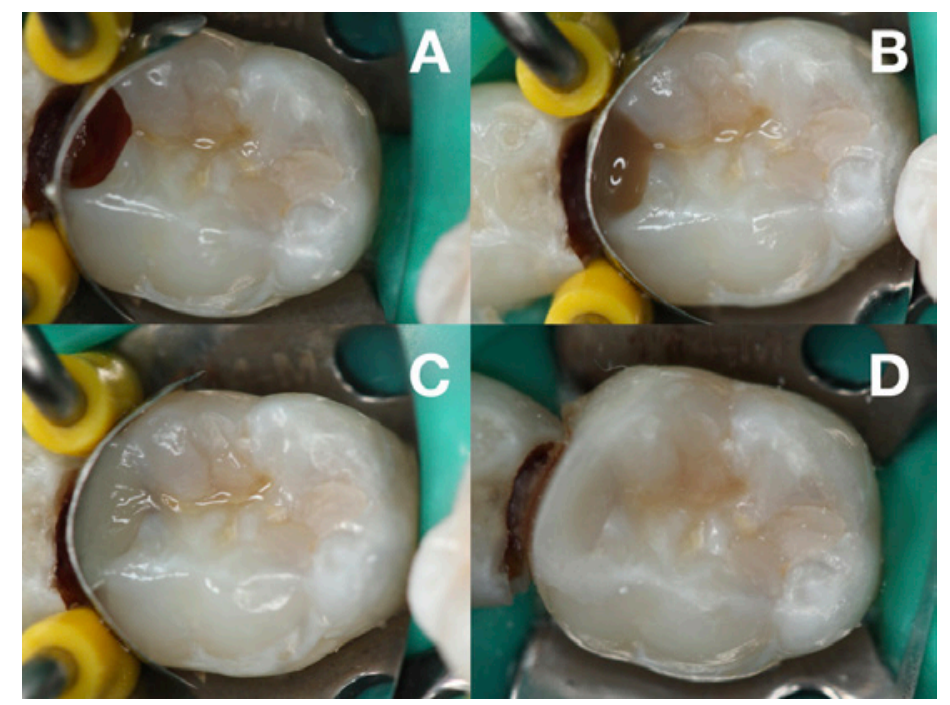

Figure 3. A) Adhesive system Ambar Universal applied; B) Composite resin bulk fill flow; C) Final cover with regular composite resin; D) Final restoration

At the end of the first session, an orthodontic rubber (Morelli, Sorocaba, SP, Brazil) was placed between the teeth 74 and 75 to gain space for restoring the tooth 74 (Figure 4).

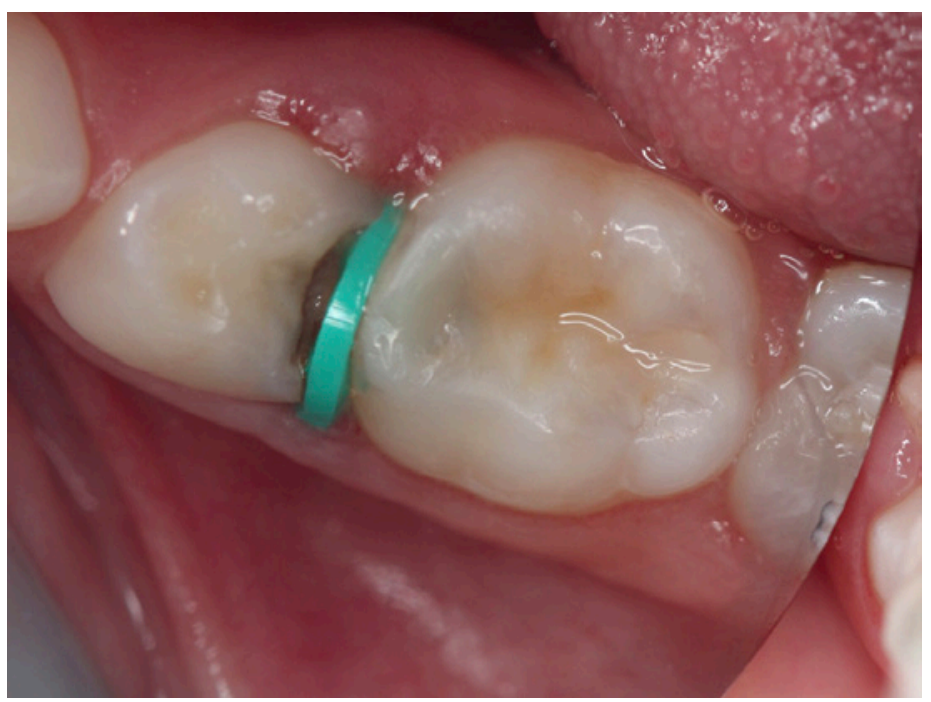

Figure 4. Installation of orthodontic rubber between 74 and 75 to gin space for restoring the tooth 74

After three days, the patient returned for another session. The orthodontic rubber was removed and a gain of space was obtained (Figure 5A). Thus, the procedure of the tooth 75 was performed. The patient was anesthetized with 2\% lidocaine. Then a rubber dam (Madeitex, São José dos Campos, SP) and clamp number W8A (SS White Duflex, Rio de Janeiro, RJ) were used. Afterwards, the caries lesion was removed with high speed bur as shown in figure $5 B$ and a steel matrix was placed (it was not adapted adequately due to the absence of the palatine wall and expulsivity of 
the deciduous tooth) (Figure 5C) and so the restoration of the tooth 75 with resin composite was executed.

Acid-etching: it was performed a selective enamel conditioning. The application was made with $37 \%$ phosphoric acid (Dentsply, Brazil) through the syringe (Figure 5D). After 15 seconds water was rinsed for 60 seconds and then dried until total evaporation from the cavity surface.

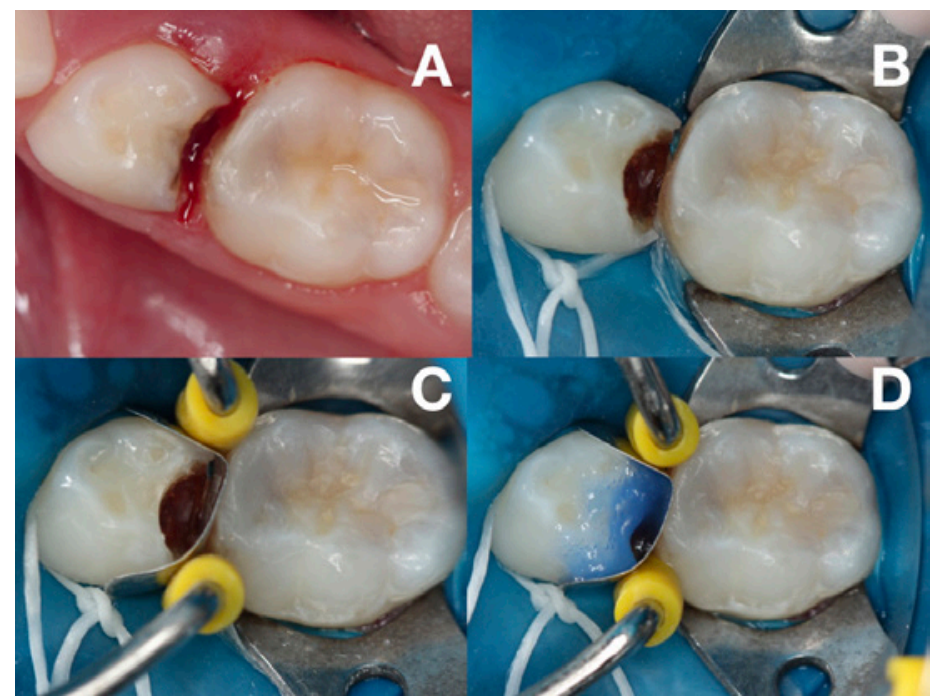

Figure 5. A) Aspect after three days about gain of space; B) Aspect final after caries lesion was removed with high speed bur; C) Steel matrix placed (note that it was impossible to adapt adequately due to the absence of the palatine wall and expulsivity of primary teeth); D) Selective enamel acid etching with $37 \%$ phosphoric acid

Adhesive system: the adhesive system Ambar Universal (FGM, Joinville - SC, Brazil) was actively applied over the cavity surface for 20 seconds, according to the manufacturer's instructions (Figure 6A). The disposable brush was agitated on the cavity surface under manual pressure. Then, for complete evaporation of the solvent, a moderate jet of clean, dry air was applied close and sufficiently strong to keep the adhesive layer in slight motion. This evaporation of the solvent continued with more forced air until there were no movements on the adhesive for at least 5 seconds. Finally, the adhesive system was photo activated for 10 seconds.

Restorative procedure: after the adhesive system application, the cavity of tooth 74 was restored with resin composite bulk fill flow Opus (FGM, Joinville - SC, Brazil). It was applied in one increment of $4 \mathrm{~mm}$ (Figure 6B) and the final cover with resin composite Llis (FGM, Joinville - SC, Brazil) (Figure 6C). The final restoration is shown in figures $6 \mathrm{D}$ and $7 \mathrm{~A}-\mathrm{B}$.

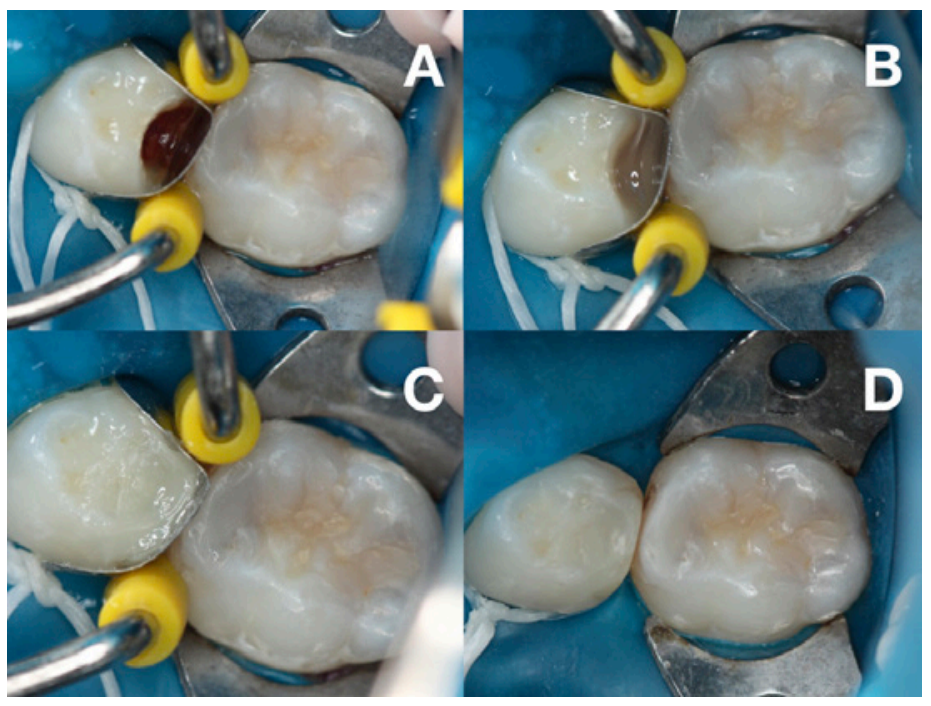

Figure 6. A) Adhesive system Ambar Universal applied; B) Composite resin bulk fill flow; C) Final cover with regular composite resin; D) Final restoration

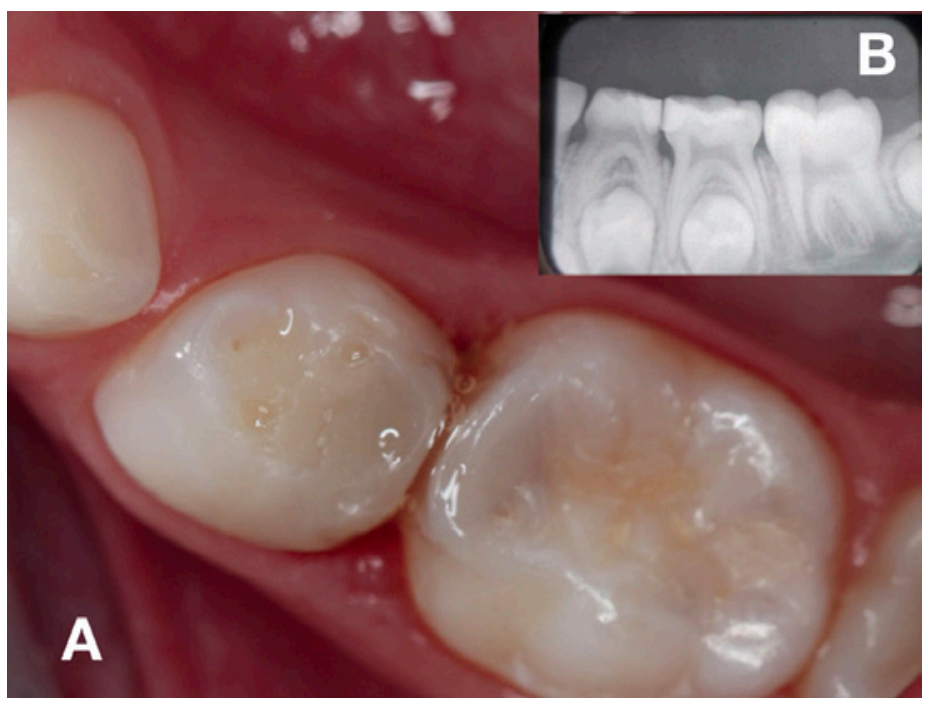

Figure 7. A) Clinical final aspect of restorations; B) Final radiography

\section{Discussion}

Approximal surfaces have been pointed as a challenge regarding the control of caries lesions in primary teeth, especially due to the larger area of contact between adjacent teeth, difficulty to clean up and limited salivary access. ${ }^{9}$ In addition, the diagnosis of incipient proximal caries remains difficult to be performed early. ${ }^{10}$

When proximal caries progress extensively into dentin, it may cause the loss of a great amount of dental structure and consequently lead to the loss of the dental mesiodistal diameter. The mesiodistal crown diameter of the primary and permanent teeth likewise plays an important role in the occlusion establishment. ${ }^{11}$ Appropriate treatment be- 
comes important to reestablish the integrity of the tooth structure lost. Additionally, before restoration of primary teeth, one needs to consider the biological cycle of primary teeth. ${ }^{12}$ Resin composite has been shown to be effective as a Class II restorative material in both the primary and permanent dentition. ${ }^{5}$ The progress of the adhesive dentistry and the advance of resin composites have allowed the use of direct resin in posterior teeth restoration. ${ }^{13}$ Time-saving restorative materials are an ongoing demand, especially in Pediatric dentistry. So, the bulk-fill resin-based composites are an attempt to minimizing the polymerization stress, besides speed up the restoration process by enabling up to 4- or 5-mm thick increments to be cured in one step, thus skipping the time-consuming layering process. The enlarged depth of cure in bulk-fill resin was realized by enhancing the materials' translucency through decreasing the filler amount and increasing the filler size. ${ }^{7}$ High viscosity bulk-fill composites have relatively higher filler content, which provides good wear resistance and satisfactory mechanical properties. Flowable bulk-fill composites generally adapt better to the cavity walls and generate lower polymerization shrinkage stresses, but they are more susceptible to wear due to their lower inorganic filler content. ${ }^{14}$ For this reason, to finish a bulk-fill resin base composite restoration by adding a $2 \mathrm{~mm}$ capping layer with a conventional resin base composite is imperative to withstand the occlusal loading. ${ }^{7,14}$ Universal adhesive systems are essentially self-etching. The manufacturers of this new adhesive modality report that these systems can be used with or without enamel and dentin conditioning. ${ }^{15}$ However, it is known that, phosphoric acid conditioning increases the bond strength of self-etching adhesives to the enamel and, therefore, the selective conditioning of enamel margins has also been recommended by some authors before the application of these new universal self-etching adhesive systems. ${ }^{16}$ In general, universal adhesive systems are versatile and easy to use, facilitating the operator, since the same product has several technical possibilities, thus reducing operative time and technical sensitivity, which is paramount important when treating children. ${ }^{15}$

\section{Conclusion}

The majority of children still present a significant level of caries disease. An early intervention is necessary, because when the teeth are affected in extensions, it may cause changes in the mesio-distal length. Restoring a tooth with inadequate contact point is a challenge to the practitioner and it is difficult to perform requiring multiple appointments. Ignore such situations or comprimise the treatment plan may prevent the success of the treatment. However, when a proper treatment is performed in association with new dental materials technologies, it ensures the recovery of the arch perimeter, minimizing the sequels of caries disease.

\section{References}

1. Frazão P. Epidemiology of dental caries: when structure and context matter. Braz Oral Res. 2012;26(Spec Iss 1):108-14.

2. Almeida RR de, Almeida-Pedrin RR de, Almeida MR. Guidelines on the Use of Space Maintainers. J Bras Ortodon Ortop Facial. 2003;8(44):157-66.

3. Carrotte P. Endodontic treatment for children. Br Dent J. 2005;198:9-15.

4. Tunison W, Flores-Mir C, El Badrawy H, Nassar U, El-Bialy T. Dental Arch Space Changes Following Premature Loss Of Primary First Molars: A Systematic Review. Ped Dent. 2008;30(4):297-302.

5. Donly KJ, García-Godoy F. The use of resin-based composite in children: an update. Ped Dent. 2015;37(2):136-43.

6. Sekhon P, Mukerji A, Restorations in the Primary Dentition and the Consequences of Inadequate Treatment Planning. Oral Health. 2017;1(6). Available on https://www.oralhealthgroup.com/features/restorations-in-the-primary-dentition-and-the-consequences-of-inadequate-treatment-planning/.

7. Ilie N, Bucuta S, Draenert M. Bulk-fill Resin-based Composites: An In Vitro Assessment of Their Mechanical Performance. Operative Dentistry. 2013;38(6):618-25.

8. Alex G. Universal Adhesives: The Next Evolution in Adhesive Dentistry? Compend Cont Edu Dent. 2015;36(1):16-26. Available on https://pdfs.semanticscholar.org/4302/b56ef843bd7f9707007c8bac80d9e2fbad93.pdf

9. Braga MM, Floriano I, Ferreira FR, Silveira JM, Reyes A, Tedesco TK, et al. Are the Approximal Caries Lesions in Primary Teeth a Challenge to Deal
With? - A Critical Appraisal of Recent Evidences in This Field. Emerging Trends in Oral Health Sciences and Dentistry. 2014;4:84-115.

10. Chaves LP, Fernandes CV, Wang L, Barata TJE, Walter LRF. Approximal caries- Bases and tools for early diagnosis. Odontol Clin-Cient. 2010;9(1):337.

11. Moorrees CFA, Thomsen SP, Jensen E, Yen PKJ. Mesiodistal Crown Diameters Of The Deciduous And Permanent Teeth In Individuals. J Dent Res. 1957;36(1):39-47.

12. Guideline on Restorative Dentistry - Clinical Practice Guidelines, American Academy of Pediatric Dentistry. 2015;37(6):232-43.

13. Hirata R, Higashi C, Masotti A. Simplificando o uso de resinas compostas em dentes posteriores. Dental Press Estet. 2004;1(1):18-34.

14. Lopes LS, Malaquias P, Calazans FS, Reis A, Loguércio AD, Barceleiro MO. Clinical strategies using universal adhesive systems: literature review with case report. Rev Bras Odontol. 2016;73(2):173-7.

15. Schliebe LRSO, Braga SSL, Pereira RAS, Bicalho AA, Veríssimo C, Novais $\mathrm{VR}$, et al. The new generation of conventional and bulk-fill composites do not reduce the shrinkage stress in endodontically-treated molars. Am J Dent. 2016;29(6):333-8.

16. Van Landuyt KL, Peumans M, De Munck J, Lambrechts P, Van Meerbeek B. Extension of a one-step self-etch adhesive into a multi-step adhesive. Dent Mat. 2006;22:533-44. 


\section{Mini Curriculum and Author's Contribution}

1. Sandra Meyfarth - DDS and MSc. Contribution: writing of the article, critical review and final approval. ORCID: 0000-0003-0074-642X

2. Roberta Barcelos - DDS and PhD. Contribution: preparation, review, and draft of the manuscript. ORCID: 0000-0003-3283-6059

3. Flavio Warol - DDS and MSc. Contribution: writing of the article, technical review. ORCID: 0000-0002-2662-751X

4. Angela Scarparo - DDS and PhD. Contribution: technical procedures; preparation and draft of the manuscript; critical review and final approval. ORCID: 00000002-4415-1893

Submitted: 09/20/2018 / Accepted for publication: 10/15/2018

Corresponding Author

Angela Scarparo

E-mail: angelascarparo@id.uff.br 